\title{
Incidence, Severity and Responses to Reportable Student Self-Harm and Suicidal Behaviours in Schools: A One-Year Population-Based Study
}

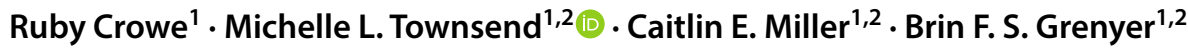

Published online: 27 August 2020

(c) The Author(s) 2020

\begin{abstract}
School staff have a unique opportunity to detect and respond to mental health issues including self-harm and suicidal behaviour in adolescents. There is limited knowledge about how these incidents are managed in schools. This study aims to understand the incidence rates, perceived severity and management of self-harm and suicidal behaviour incidents by schools. A total of 1525 school incidents were analysed for rate, severity and response. Pearson's $\chi^{2}$ test was used to understand incident rates of self-harm and suicidal behaviours compared to all other incidents, and if incident category was related to emergency service involvement. A Kruskal-Wallis ANOVA analysed differences in severity ratings for incidents, and relative risk ratios determined the probability that first responder services will be engaged in self-harm and suicidal behaviour incidents. Self-harm and suicidal behaviour incidents $(n=77)$ accounted for $5.05 \%$ of all incidents and were more likely to be rated highly severe compared to other incidents. Incidents of self-harm and suicidal behaviours were 1.43 times more likely to have police involvement and 8.37 times more likely to have ambulance involvement compared to other incidents that caused harm to students, staff or property including welfare and violence incidents. The findings highlight the severity of reportable self-harm and suicidal behaviour incidents as they required an emergency response. We discuss the potential missed opportunity for early intervention by school staff and services, which may hinder future disclosure or help-seeking by at-risk young people. Training of school staff may provide knowledge and confidence to respond appropriately to self-harm and suicidal behaviour incidents and prevent escalation requiring emergency intervention.
\end{abstract}

Keywords Self-harm $\cdot$ Suicidal $\cdot$ Adolescent $\cdot$ Adolescence $\cdot$ School $\cdot$ Students

\section{Introduction}

Self-harm and suicidal behaviour among young people is a major public health concern (Hawton, Saunders, \& O'Connor, 2012). Rates of self-harm in adolescents are

Michelle L. Townsend

mtownsen@uow.edu.au

Ruby Crowe

rc127@uowmail.edu.au

Caitlin E. Miller

millerc@uow.edu.au

Brin F. S. Grenyer

grenyer@uow.edu.au

1 School of Psychology, Building 22, University of Wollongong, Wollongong, NSW 2522, Australia

2 Illawarra Health and Medical Research Institute, University of Wollongong, Wollongong, NSW 2522, Australia increasing, with an average lifetime prevalence rate of $16.1-18 \%$ in adolescents aged between 11 and 18 years in international data analysed from 52 studies (Muehlenkamp, Claes, Havertape, \& Plener, 2012). For adolescents aged between 13 and 18 years in USA, there is an estimated lifetime prevalence of $12.1 \%$ for suicidal ideation, $4.0 \%$ for suicide plans and $4.1 \%$ for suicide attempts (Nock et al., 2013).

While definitions vary, self-harm typically refers to the intentional physical harm to oneself, which can include a myriad of behaviours such as cutting, burning, hitting, scratching or overdosing on medication or illicit drugs (Grenyer, Gray, \& Townsend, 2016). Suicidal behaviour may refer to nonfatal suicidal ideation, plans and suicide attempts (Nock et al., 2008). Young people who self-harm are 4 times more likely to die by suicide than individuals without a self-harm history (O'Connor, Rasmussen, \& Hawton, 2012); however, acts of self-harm may serve a wide range of functions for young people and do not necessarily 
indicate suicidal intent or behaviour (Laye-Gindhu \& Schonert-Reichl, 2005).

School staff have a unique role in the detection and response to mental health issues, including self-harm and suicidal behaviours (Hasking et al., 2016; Townsend, Gray, Lancaster, \& Grenyer, 2018a). In a survey of 15-19 year olds, $36 \%$ reported they would go to a teacher if they needed help while $30.4 \%$ reported they would turn to a school counsellor (Carlisle et al., 2019). Trusted, supportive and available adults such as school staff are important in adolescent helpseeking, particularly for students who would not otherwise seek help such as those with limited emotional competence and negative perceptions towards seeking and receiving help (De Riggi, Moumne, Heath, \& Lewis, 2016). As consistent and often trusted figures in adolescent's lives, school staff may also serve as important resources for adolescents experiencing the help-negation effect. This refers to how adolescents experiencing suicidal ideation may avoid seeking help from families or health professionals when experiencing suicidal ideation (Rickwood, Deane, Wilson, \& Ciarrochi, 2005; Wilson \& Deane, 2010; Wilson, Deane, Marshall, \& Dalley, 2010). Further, schools are important in the identification and intervention for self-harm and suicidal behaviour as for many young people there is a lack of access to mental health services and poor service utilisation (McGorry, Bates, \& Birchwood, 2013). In the USA, it is estimated that up to half of adolescents with severe mental disorders have never received any treatment for their mental health, and approximately twothirds of adolescents with any mental health disorder do not receive mental health services (Merikangas et al., 2011).

Despite the importance of school staff for young people who may be engaging in self-harm or suicidal behaviours and staff willingness to assist young people who self-harm, there are barriers at both system- and school-level for staff. In an Australian study of secondary school staff, $69.5 \%$ reported they had encountered at least one incident of self-harm with a student; however, $80.4 \%$ indicated they have never received education regarding self-harm (Berger, Hasking, \& Reupert, 2013b). Teachers reported they lack confidence and skills to be able to manage self-harm incidents effectively and feel frustrated by limited support in the wider system for these young people (Berger et al., 2013b). A review of the role of schools in self-harm and suicidal behaviour found that both students and staff report the absence of self-harm and suicidal behaviour education may contribute to ineffective responses to these issues in schools (Evans \& Hurrell, 2016).

Given the importance of school staff in management of student self-harm and suicidal behaviours, it is important to understand how schools currently manage these incidents. A review of self-harm in Canadian schools noted that initial responses to self-harm by young people are critical in influencing future help-seeking and willingness to disclose selfharm (De Riggi, Heath, \& Lewis, 2018). Strong emotional reactions from school staff may result in students experiencing feelings of alienation and may increase distress, thereby possibly reinforcing future self-harm acts (Toste \& Heath, 2010). There have also been indications that self-harm or suicidal behaviour incidents may be escalated to external emergency services more often than other school incidents based on fear and lack of education of staff (Evans \& Hurrell, 2016). To the authors' knowledge, no studies have investigated the response of schools to self-harm and suicidal behaviour incidents compared to other types of incidents and therefore there is limited knowledge of the incident rate, perceived severity and management of self-harm and suicidal behaviour within schools. As schools are an important setting for identification and intervention of self-harm and suicidal behaviour, it is critical to understand how schools currently react to and manage these incidents in order to determine what changes can be made to better support young people at school. Departmental policy in New South Wales (NSW) Australia mandates school principals centrally report any incidents which cause harm to the student, staff, property or others including self-harm and suicidal behaviour. The current population-based study has three aims-(1) provide incidence rates of self-harm and suicidal behaviour in all NSW primary and secondary schools, (2) understand the perceived severity of self-harm and suicidal behaviour incidents compared to other incidents that cause harm to students, staff or property and (3) examine the relationship between incident type and emergency service involvement. We hypothesise self-harm and suicidal behaviour incidents will be less frequent than other incidents but will be treated as more severe and escalated to emergency services more often than other incidents.

\section{Methods}

\section{Participants}

Archival anonymous data were accessed from the Safety and Security Directorate's Incident Reporting system established by NSW Department of Education and published in the public domain (NSW Department of Education). In the 12-month period, July 2015-June 2016, there were 1525 reports of incidents which caused harm to a student, staff or property lodged by school principals. As a significant portion of the information in incident reports was redacted by NSW Department of Education to protect the student and school's privacy, there was restricted information on demographic variables. Most incidents reported were from a major city of Australia $(n=678$, $44.5 \%)$. A quarter (24.8\%) of incidents were from an unknown area, followed by inner regional Australia $(n=366,24 \%), 3.7 \%$ from remote Australia and 3.1\% from outer regional Australia. Only $24.8 \%$ of incident reports contained information 
regarding principal networks and location. These 378 reports originated from 66 unique principal networks, representing $60 \%$ of total principal networks in NSW. It was not possible to analyse data on school year, age or gender, as these variables were not typically available in the dataset to ensure confidentiality of the student. As all data were anonymous and publicly available, ethics approval by an Institutional Review Board was not needed.

\section{Procedure}

Incident reports from 1 July 2015 to 30 June 2016 were reviewed. Reports included incidents involving violence, weapons, drugs, technology, welfare (including self-harm and suicidal behaviour incidents, student welfare concerns and child approach/intimidate), and other (including fire lighting, malicious damage, bomb threats and indecent exposure). Each incident report was reviewed and coded for incident type, year, school term, actions taken, severity, and police and ambulance involvement. An explanation of the codes and an example is presented in Table 1. The code of 'suicidal intention' referred to suicidal ideation that was current and expressed at school. It should also be noted that the category coded as 'suicide' included suicides that occurred off school property and out of school hours, however, were still included in analyses to understand actions that schools take in different circumstances. Two raters independently coded 30 welfare incident reports chosen at random to assess agreement of self-harm and suicidal behaviour incidence and severity rating. Inter-rater reliability was high (Cohen's kappa $=.95)$.

\section{Data Analysis}

Data analysis was performed using SPSS version 23. Several self-harm or suicidal behaviour incidents were coded in two categories. Three incidents were recorded under the 'drugs' category, five incidents in the 'violence' category and two incidents in the 'weapons' category were also coded as 'selfharm'. These incident categories reflected the form of selfharm or suicidal behaviours including usage/consumption of drugs and prohibited weapons including knives. Given the focus on self-harm and suicidal behaviour in this research, these items were recoded into the 'welfare' category to account for the self-harm component. Two incidents within the welfare category were coded both as 'student welfare concern' and 'self-harm' and so were recoded to reflect 'selfharm' as the primary incident type. Further, some incidents reported both self-harm and suicidal ideation or attempt. These incidences were categorised by the primary incident type recorded by principals. To account for this, self-harm, suicide intention, suicide attempt and suicide were included in the analysis as 'self-harm and suicidal behaviours'.
In order to answer aim 1, descriptive information was analysed including incident type and frequency, region, year and school term. To answer aim 2, severity ratings for self-harm and suicidal behaviour incidents were reported, in addition to action taken by school and involvement of parents or guardians. A Kruskal-Wallis ANOVA was used to analyse difference in severity ratings with and without self-harm or suicidal behaviour. For aim 3, a Pearson's $\chi^{2}$ evaluated if incident category is related to whether police involvement and ambulance involvement occurs in an incident. Relative risk was used to determine the probability that police and ambulance services will occur in self-harm and suicidal behaviour incidents compared to all other incidents.

\section{Results}

\section{Aim 1: Incidence Rates of Self-Harm and Suicidal Behaviour in All NSW Primary and Secondary Schools}

The total number of incident reports by category is reported in Table 2. Within the welfare category, there were 49 incidents of self-harm, 13 incidents coded as suicidal intentions, 6 incidents coded as suicide attempt and 9 incidents coded as completed suicide, with a total of 77 self-harm or suicidal behaviour incidents. These categories represent $5.05 \%$ of all incidents. Within the welfare category, incidents relating to self-harm and suicidal behaviour accounted for $28.4 \%$ of incidents. Descriptive statistics for incidents involving selfharm and suicidal behaviour are reported in Table 3.

\section{Aim 2: Understand Perceived Severity of Self-Harm and Suicidal Behaviour Incidents Compared to Other Incidents}

Of the 77 self-harm and suicidal behaviour incidents, the most common severity rating was highly severe-external action taken with emergency service involvement (62.3\%), followed by internal action with or without student involvement $(22.1 \%)$, external action taken with parental involvement $(9.1 \%)$ and no action taken (3.9\%). The severity ratings of incidents are shown in Fig. 1.

In most instances, there was limited interaction reported between schools and parents or guardians following self-harm or suicidal behaviour incidents-in $63.6 \%$ of incidents only the student was involved, in $24.7 \%$ of incidents both the student and parent were involved and in only $2.6 \%$ of incidents were the parents only involved. In $9.1 \%$ of incidents, the school did not collaborate with anyone. Counselling action was taken by the school in $81.8 \%$ of self-harm and suicidal behaviour incidents. There was police involvement in 29 (37.7\%) self-harm and suicidal 
Table 1 Incident types and coding scheme

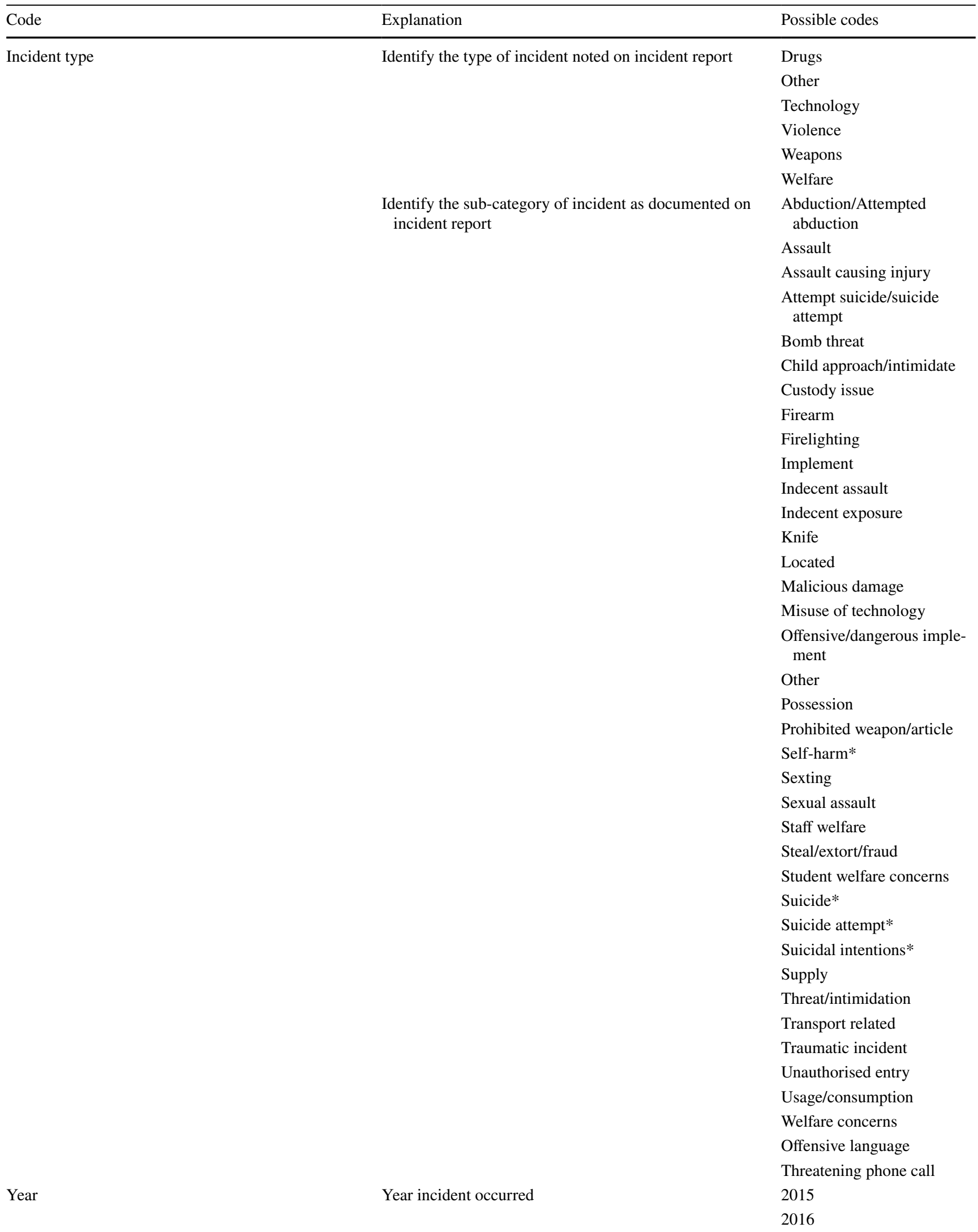


Table 1 (continued)

\begin{tabular}{|c|c|c|}
\hline Code & Explanation & Possible codes \\
\hline School term & School term incident occurred & $\begin{array}{l}\text { Term } 1 \\
\text { Term } 2 \\
\text { Term } 3 \\
\text { Term } 4\end{array}$ \\
\hline Actions taken & $\begin{array}{l}\text { Whether internal, external, or no action was taken at the } \\
\text { time of the incident } \\
\text { " "Internal action" refers to actions taken by school staff } \\
\text { within the school } \\
\text { - "External action" refers to any external agencies } \\
\text { consulted or involved, including police and ambulance } \\
\text { services } \\
\text { - "Counselling" refers to if the school stated they pro- } \\
\text { vided counselling to the student } \\
\text { - "Parent involvement" if a parent/guardian attended } \\
\text { the school and was involved with the student/s in the } \\
\text { report. Note the term parent refers to both parents and } \\
\text { guardians }\end{array}$ & $\begin{array}{l}\text { Internal action } \\
\text { External action } \\
\text { Both internal and external } \\
\quad \text { action } \\
\text { No action } \\
\text { Counselling } \\
\text { Parent involvement }\end{array}$ \\
\hline Severity rating & $\begin{array}{l}\text { Determined by the perceived severity of the incident and } \\
\text { actions that occurred. Actions were rated: } \\
\text { - "Highly severe" if the report involved external action } \\
\text { with emergency services } \\
\text { " "Severe" if the report involved external action with } \\
\text { parents } \\
\text { - "Moderate" if the report involved internal action with } \\
\text { the student and staff/other students } \\
\text { - Mild" if the report involved no action or internal } \\
\text { action with/without the student }\end{array}$ & $\begin{array}{l}\text { Mild } \\
\text { Moderate } \\
\text { Severe } \\
\text { Highly severe }\end{array}$ \\
\hline \multirow[t]{2}{*}{ Police involvement } & $\begin{array}{l}\text { If police attended or were involved with the student/s in } \\
\text { the report }\end{array}$ & Police involved \\
\hline & & No police involvement \\
\hline \multirow[t]{2}{*}{ Ambulance involvement } & $\begin{array}{l}\text { If an ambulance attended or was involved with the } \\
\text { student/s in the report }\end{array}$ & Ambulance involved \\
\hline & & No ambulance involvement \\
\hline \multicolumn{3}{|c|}{ Example incident and coding } \\
\hline Description of incident & Codes & Codes applied \\
\hline
\end{tabular}


Table 1 (continued)

\begin{tabular}{|c|c|c|}
\hline Code & Explanation & Possible codes \\
\hline $\begin{array}{l}\text { Report SSD-2015-03007 } \\
\text { A Year [redacted] male (YP) absconded from school } \\
\text { and threatened self-harm, standing in the middle of } \\
\text { the road. The YP was holding a stick and was using } \\
\text { it to strike cars on the road and in the car park. The } \\
\text { YP was coerced back into school and taken into a } \\
\text { room where he proceeded to smash the lights in the } \\
\text { ceiling. The YP smashed windows and deliberately } \\
\text { [redacted] } \\
\text { The YP's carer, police and NSW Ambulance were } \\
\text { contacted and attended } \\
\text { Actions } \\
\text { - An ambulance attended } \\
\text { - The school called for an ambulance to attend the } \\
\text { school } \\
\text { - Police attended the school } \\
\text { - The school contacted the police } \\
\text { - The school was advised to contact the Director, } \\
\text { Public Schools NSW } \\
\text { - The school was advised to recommend affected staff } \\
\text { to contact the Employee Assistance Program on } \\
\text { 1300 } 360364 \\
\text { - The carer of the YP attended the school } \\
\text { - The school contacted the carer of the YP } \\
\text { - The YP } 1 \text { was conveyed from the school by ambu- } \\
\text { lance } \\
\text { - Disciplinary action was taken by the school in rela- } \\
\text { tion to the YP } \\
\text { - The school was advised to create/review the risk } \\
\text { management plan for the YP prior to their return to } \\
\text { school } \\
\text { counselling to the YP }\end{array}$ & $\begin{array}{l}\text { Severity rating } \\
\text { Police involvement } \\
\text { Ambulance involvement }\end{array}$ & $\begin{array}{l}2015 \\
3 \\
\text { Internal and external action } \\
\text { Parent involvement } \\
\text { Counselling } \\
\text { Highly severe } \\
\text { Police involvement } \\
\text { Ambulance involvement }\end{array}$ \\
\hline
\end{tabular}

*Incident subcategories classed as 'self-harm or suicidal behaviour'

$Y P$ young person

Table 2 Incident reports in NSW schools between July 2015 and June 2016

\begin{tabular}{lc}
\hline Incident category & $\begin{array}{l}\text { Number of } \\
\text { incidents }(\%)\end{array}$ \\
\hline Violence & $611(40.1)$ \\
Drugs & $252(16.5)$ \\
Weapons & $163(10.7)$ \\
Technology & $129(8.5)$ \\
Other & $100(6.6)$ \\
Welfare & $270(17.7)$ \\
Self-harm and suicidal behaviour & $77\left(5.1^{*}\right)$ \\
$\quad$ Completed suicide & $9\left(0.6^{*}\right)$ \\
Suicide attempt & $6\left(0.4^{*}\right)$ \\
Suicidal intentions & $13\left(0.9^{*}\right)$ \\
Self-harm & $49\left(3.2^{*}\right)$ \\
\hline
\end{tabular}

$N=1525 . *$ Percentage of total incidents behaviour incidents and ambulance involvement in 43 (55.8\%) incidents (Table 4). Incident reports involving selfharm or suicidal behaviour $(n=77)$ were analysed and compared to the remaining sample $(N=1448)$. A Kruskal-Wallis ANOVA showed there was a statistically significant difference in severity rating between incident types involving self-harm or suicidal behaviour (Mean Rank $=909.57$ ) and incidents without self-harm or suicidal behaviour (Mean Rank $=755.21), \chi^{2}(1)=9.78, p=.002$. This indicates that incidents involving self-harm or suicidal behaviour were statistically more likely to result in a higher severity rating-meaning they more often resulted in external agency involvement.

\section{Aim 3: Examine the Relationship Between Incident Type and Emergency Service Involvement}

Prevalence of incident reports involving police or ambulance services was analysed. Police were involved in 459 (30.1\%), and ambulance services were involved in $233(15.3 \%)$ of all 
Table 3 Descriptive statistics of incidents involving self-harm and suicidal behaviour

\begin{tabular}{lc}
\hline Variable & $\begin{array}{l}\text { Number of self-harm and sui- } \\
\text { cidal behaviour incidents }(\%)\end{array}$ \\
\hline Region & $33(42.9)$ \\
Major city Australia & $13(6.9)$ \\
Inner regional Australia & $3(3.9)$ \\
Remote Australia & $28(36.4)$ \\
Unknown & \\
Year & $31(40.3)$ \\
2015 & $20(26.0)$ \\
2016 & $26(33.8)$ \\
Unknown & \\
School term & $6(7.8)$ \\
Term 1 & $14(18.2)$ \\
Term 2 & $13(16.9)$ \\
Term 3 & $18(23.4)$ \\
Term 4 & $26(33.8)$ \\
Unknown
\end{tabular}

$n=77$

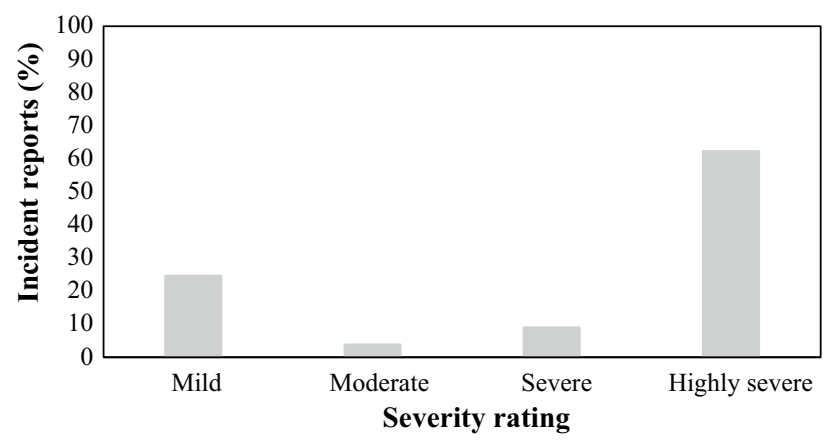

Fig. 1 Severity rating of incidents involving self-harm or suicidal behaviour

incidents (see Table 5). There were 123 (8.1\%) incidents involving both ambulance and police. Pearson's $\chi^{2}$ independence test was used to evaluate whether incident category was related to police or ambulance involvement in an incident report. Incident category was related to police involvement, $\chi^{2}(5, N=1525)=50.66, p<.001$, although the association was small $\left(\varphi_{c}=.18\right)$. Incident category was related to ambulance involvement, $\chi^{2}(5, N=1525)=205.02, p<.001$, and the association between ambulance involvement and incident category was medium $\left(\varphi_{c}=.37\right)$. Table 5 shows the crosstabulation for the tests.

The probability that police and ambulance services will occur in self-harm and suicidal behaviour incidents compared to all other incidents was analysed. Police were involved in 29 (37.7\%) of self-harm and suicidal behaviour incident reports; however, a Pearson's $\chi^{2}$ independence test showed that incidents of self-harm and suicidal behaviour were not significantly related to police involvement, $\chi^{2}(1)=2.20, p=.138$ with $\varphi_{c}=.04$ (see Table 6 for crosstabulations). Relative risk ratio calculations found incidents of self-harm and suicidal behaviour were 1.43 times more likely to have police involvement compared to all other incident reports, 95\% CI [0.90, 2.30].

Ambulance services were involved in 43 (55.8\%) of self-harm and suicidal behaviour reports. A Pearson's $\chi^{2}$ independence test showed that incidents of self-harm and suicidal behaviour were significantly related to ambulance involvement, $\chi^{2}(1)=103.10, p<.001$ with $\varphi_{c}=.26$ (see Table 6 for cross-tabulations). Incidents of self-harm and suicidal behaviour were 8.37 times more likely to have ambulance involvement compared to all other incident reports, 95\% CI [5.21, 13.47].

\section{Discussion}

The current study investigated the reporting by school principals of self-harm and suicidal behaviour incidents to understand the perceived severity of and response to selfharm and suicidal behaviours by schools. One-thousand, five-hundred and twenty-five incident reports were identified and analysed, with 77 incidents of self-harm or suicidal behaviour. We hypothesised incidents involving self-harm and suicidal behaviour would be less frequent than other
Table 4 Police and ambulance involvement for self-harm and suicidal behaviour incidents

\begin{tabular}{lccc}
\hline Incident type & $\begin{array}{l}\text { Total number of } \\
\text { incidents }\end{array}$ & $\begin{array}{l}\text { Number of incidents with } \\
\text { police involvement }(\%)\end{array}$ & $\begin{array}{l}\text { Number of incidents with } \\
\text { ambulance involvement (\%) }\end{array}$ \\
\hline Completed suicide* & 9 & $1(11.1)$ & $0(0)$ \\
Suicide attempt & 6 & $3(50)$ & $4(66.7)$ \\
Suicidal intentions & 13 & $5(38.5)$ & $7(53.8)$ \\
Self-harm & 49 & $20(40.8)$ & $32(65.3)$ \\
Total & 77 & $29(37.7)$ & $43(55.8)$ \\
\hline
\end{tabular}

$n=77$, *outside of school, percentages represent the number of incidents with emergency service involvement when accounting for all number of incidents of each type 
Table 5 Cross-tabulation of police and ambulance involvement and incident types

\begin{tabular}{|c|c|c|c|}
\hline & \multicolumn{2}{|l|}{ Police involvement } & \multirow[t]{2}{*}{ Tota } \\
\hline & No police involvement & Police involvement & \\
\hline \multicolumn{4}{|l|}{ Incident type } \\
\hline Drugs & 184 & 68 & 252 \\
\hline Other & 45 & 55 & 100 \\
\hline Technology & 111 & 18 & 129 \\
\hline Violence & 419 & 192 & 611 \\
\hline Weapons & 124 & 39 & 163 \\
\hline Welfare & 183 & 87 & 270 \\
\hline \multirow[t]{3}{*}{ Total } & 1066 & 459 & 1525 \\
\hline & \multicolumn{2}{|l|}{ Ambulance involvement } & Total \\
\hline & No ambulance involvement & Ambulance involvement & \\
\hline \multicolumn{4}{|l|}{ Incident type } \\
\hline Drugs & 238 & 14 & 252 \\
\hline Other & 89 & 11 & 100 \\
\hline Technology & 129 & 0 & 129 \\
\hline Violence & 517 & 94 & 611 \\
\hline Weapons & 160 & 3 & 163 \\
\hline Welfare & 159 & 111 & 270 \\
\hline Total & 1292 & 233 & 1525 \\
\hline
\end{tabular}

Table 6 Rates of police and ambulance involvement for incidents with and without self-harm and suicidal behaviour and incident types

\begin{tabular}{llll}
\hline & Police involvement & \\
\cline { 2 - 3 } & No police involvement (\%) & Police involvement (\%) \\
\hline Incident type & & \\
Self-harm or suicidal behaviour & $48(62.3)$ & $29(37.7)$ & 77 \\
No self-harm or suicidal behaviour & $1018(70.3)$ & $430(29.7)$ & 1448 \\
Total & $1066(69.9)$ & $459(30.1)$ & 1525 \\
\hline & Ambulance involvement & Total \\
\cline { 2 - 3 } & No ambulance involvement $(\%)$ & & \\
\hline Incident type & & $43(55.8)$ & $190(13.2)$ \\
Self-harm or suicidal behaviour & $34(44.2)$ & $233(15.3)$ \\
No self-harm or suicidal behaviour & $1258(86.9)$ & 77 \\
Total & $1292(84.7)$ & 1448 \\
\hline
\end{tabular}

incidents reported. Self-harm or suicidal behaviour incidents accounted for $5.05 \%$ of total incidents and were less frequent than assault or threat incidents. We also hypothesised incidents involving self-harm or suicidal behaviour were more likely to be rated severe compared to other incidents that cause harm to students, staff or property. This hypothesis was supported-self-harm or suicidal behaviour incidents were significantly more likely to result in escalation to an external agency and categorised as a highly severe incident. Lastly, we sought to examine the relationship between incident type and emergency service involvement. Relative risk ratios found that police were 1.43 times more likely and ambulance services were 8.37 times more likely to be involved in an incident of self-harm or suicidal behaviour compared to all other incident categories.

Prevalence rates of incidents involving self-harm and suicidal behaviours in this study are lower than the current estimates for young people in Australia (Martin, Swannell, Hazell, Harrison, \& Taylor, 2010; Zubrick et al., 2016). This may reflect the nature of incident reports in that principals only reported current suicidal ideation which occurred at school. It may also suggest many incidents of self-harm or 
suicidal behaviour by young people are not known (i.e. hidden by the young person) and, therefore, are not filed as an incident report by a school principal. As the physical indications of self-harm or suicidal behaviour are not always obvious in the school environment, it is possible that school staff may lack understanding of risk factors and common behaviours associated with self-harm or suicidal behaviour among young people. Research indicates less than $33 \%$ of high school teachers report being knowledgeable about self-harm which likely hinders appropriate identification of self-harm or related behaviours (Heath, Toste, Sornberger, \& Wagner, 2010). Risk factors which could be identified in schools may include personality vulnerabilities like perfectionism, impulsivity and self-criticism and cognitive vulnerabilities such as deficits in social interaction and problem-solving (Hawton et al., 2012). Further, interpersonal difficulties, depressive episodes, and emotion dysregulation are indicated as factors associated with self-harm and suicidal behaviour (Adrian, Zeman, Erdley, Lisa, \& Sim, 2011; Hawton \& James, 2005). By understanding risk factors and common behaviours associated with mental distress, school staff may be able to better identify young people who are self-harming or at risk of suicidal behaviour. In order to achieve this, school staff require resources and supportive training in mental health among young people. This would develop knowledge and foster confidence to respond appropriately. Specifically, programs aimed at providing psychological education for teachers regarding identification of risk factors and antecedents to self-harm and suicidal behaviour would be most effective. Furthermore, ensuring that all teachers are aware of colleagues that are knowledgeable in identifying and responding to welfare concerns including self-harm and suicidal behaviour (for example, school counsellor, head teacher of wellbeing, school executive) is important.

Considering school staff are likely to encounter self-harm or suicidal behaviours by young people at school and may be a supportive and non-judgemental adult in the young person's life, the response of school staff as first responders to self-harm and suicidal behaviour incidents is extremely important. We found that incidents of self-harm or suicidal behaviour that were reported by school principals were more likely to be escalated to external emergency services compared to other incidents. These findings support previous qualitative research that schools rate incidents of self-harm and suicidal behaviour as severe and have a tendency to escalate incidents in an attempt to provide adequate support to the student (Evans \& Hurrell, 2016). It has been reported that schools often respond to self-harm incidents in a manner of fear, denial or panic and immediate referral to external supports (Dowling \& Doyle, 2016). While involving emergency services may sometimes be necessary for medical attention-particularly when a student is presenting with concurrent self-harm and suicidal behaviours-escalating self-harm incidents to external emergency services when risk is not imminent is advised against in best-practice guidelines (Hasking et al., 2016). Such an escalation of response would be made in an effort to provide appropriate care to students, but there may be harmful consequences of responding in this way. Unnecessary referrals to external emergency services may result in a break of trust between students and staff and lead to future non-disclosure (Evans \& Hurrell, 2016). Young people may feel that their needs for empathic understanding and validation with adults who they feel comfortable talking to are not met if immediate referral occurs (Berger, Hasking, \& Martin, 2013a). Young people report they approach adults for advice and problemsolving in relation to self-harm, and through the escalating to external services, school staff may miss an opportunity to connect with adolescents at risk and intervene in an compassionate way that protects the dignity of the young person. However, where there is imminent risk, escalation to emergency services is necessary (Townsend, Hasleton, Marceau, Gray, \& Grenyer, 2018b). Providing schools with structured responses can assist the capacity of schools to plan and implement strategies to support students (Townsend et al., 2018a).

The data reported here may also indicate that early nonsevere incidents of self-harm are not being identified or are being managed at a school and family level. The more severe incidents that meet the threshold for reporting may be responded to with an emergency services response. This escalation of responses to self-harm and suicidal behaviour incidents may reinforce the stigma associated with self-harm and the desire to keep it hidden (Evans \& Hurrell, 2016; Heath et al., 2010). Young people have reported that crucial factors in helping people who self-harm include reducing judgement from parents and teachers and reducing stigma (Berger et al., 2013b). If a self-harm incident is responded to with escalation, the young person may interpret this as indication that they are perceived as unstable or suicidal. This may unintentionally perpetuate the stigma associated with self-harm and contribute to future non-disclosure.

A primary limitation of this study is the inability to distinguish between self-harm and suicidal behaviours due to the limited number of these incidents and lack of detailed case data. Although there is an overlap between self-harm and suicidal behaviour, they may serve different functions and may present as differing in severity-something that can only be studied if detailed qualitative case data were available. Therefore, it is possible that schools respond differently to these incidents-and in the case of suicide attempts or serious self-harm escalation to external agencies would be made due to the nature of these individual factors. Future studies should aim to differentiate between school responses to self-harm, suicidal intentions, suicide attempts and suicide by seeking more detailed case-based 
data. Further studies could also investigate the possibility of screening for self-harm and suicidal behaviours in the school setting. This study was also limited by only having access to incidents that had been reported, and it is possible other incidents had occurred that were not documented and managed without escalation to emergency services. Incident report data did not identify the ages or gender of the students involved in each incident and further studies could investigate the impact of age upon self-harm and suicidal behaviour presentation in schools. It will also be important for future studies to identify if size of schools, proportion of Indigenous or racially diverse students and income levels or socio-economic rating of the school area impacts on actions the school takes in responding to selfharm and suicidal behaviour. As families with low socioeconomic status and people in ethnic minorities are at higher risk of developing mental health disorders (Gary, 2005; Reiss, 2013) and schools with higher proportions of these students may respond differently to mental health issues. Further studies could also seek to understand the prevalence of self-harm or suicidal behaviour throughout the school year, and understand how this may impact on the role of school staff in responding to incidents. Importantly, research is required to develop and critically evaluate training programs for implementation with school staff that focus on psychoeducation of self-harm and suicidal behaviour and practical strategies. These programs may include a decision-making model for the school in determining appropriate responses to best support students who engage in self-harm or suicidal behaviours. Finally, research is critically needed to understand how helpful students perceive the actions that were taken to be in supporting them when in distress and what the longer term outcomes are for these students.

School staff need the knowledge and confidence to respond to self-harm and suicidal behaviour incidents in a way that is non-judgemental and empathetic, while still expressing concern for the young person. As important figures in young people's lives, it is imperative that school staff are adequately trained to provide the best support without escalating to external services in cases where emergency services are not needed. Training of school staff is therefore needed to provide staff with knowledge of appropriate and empathic reactions to a young person's disclosure of selfharm or suicidal behaviour. The current policies should be updated to reflect best-practice guidelines (Hasking et al., 2016), and actions should be implemented to provide appropriate support for students. Furthermore, there is a need for effective and accessible mental health services within the school system and outside that can work collaboratively to ensure young people experiencing mental health difficulties receive the care they need early in the genesis of their difficulties.
Acknowledgements The Project Air Strategy acknowledges the support of the New South Wales Ministry of Health.

Funding This research did not receive any specific grant from funding agencies in the public, commercial, or not-for-profit sectors.

Availability of Data and Material The data are freely available from the NSW Safety and Security Directorate's Incident Reporting system.

\section{Compliance with Ethical Standards}

Conflict of interest There are no conflicts of interest to report.

Open Access This article is licensed under a Creative Commons Attribution 4.0 International License, which permits use, sharing, adaptation, distribution and reproduction in any medium or format, as long as you give appropriate credit to the original author(s) and the source, provide a link to the Creative Commons licence, and indicate if changes were made. The images or other third party material in this article are included in the article's Creative Commons licence, unless indicated otherwise in a credit line to the material. If material is not included in the article's Creative Commons licence and your intended use is not permitted by statutory regulation or exceeds the permitted use, you will need to obtain permission directly from the copyright holder. To view a copy of this licence, visit http://creativecommons.org/licenses/by/4.0/.

\section{References}

Adrian, M., Zeman, J., Erdley, C., Lisa, L., \& Sim, L. (2011). Emotion dysregulation and interpersonal difficulties as risk factors for nonsuicidal self-injury in adolescent girls. Journal of Abnormal Child Psychology, 39(3), 389-400. https://doi.org/10.1007/ s10802-010-9465-3.

Berger, E., Hasking, P., \& Martin, G. (2013a). 'Listen to them': Adolescents' view on helping young people who self-injure. Journal of Adolescence, 36(5), 935-945. https://doi.org/10.1016/j.adole scence.2013.07.011.

Berger, E., Hasking, P., \& Reupert, A. (2013b). "We're working in the dark here": Education needs of teachers and school staff regarding student self-injury. School Mental Health, 6(3), 201212. https://doi.org/10.1007/s12310-013-9114-4.

Carlisle, E., Fildes, J., Hall, S., Perrens, B., Perdriau, A., \& Plummer, J. (2019). Youth survey report 2019. Sydney: Mission Australia.

De Riggi, M. E., Heath, N. L., \& Lewis, S. P. (2018). Brief report: Nonsuicidal self-injury in adolescence: turning to the Internet for support. Counselling Psychology Quarterly, 31(3), 397-405. https://doi.org/10.1080/09515070.2018.1427556.

De Riggi, M. E., Moumne, S., Heath, N. L., \& Lewis, S. P. (2016). Non-suicidal self-injury in our schools: A review and researchinformed guidelines for school mental health professionals. Canadian Journal of School Psychology, 32(2), 122-143. https ://doi.org/10.1177/0829573516645563.

Dowling, S., \& Doyle, L. (2016). Responding to self-harm in the school setting: The experience of guidance counsellors and teachers in Ireland. British Journal of Guidance and Counselling, 45(5), 583-592. https://doi.org/10.1080/03069 885.2016 .1164297$.

Evans, R., \& Hurrell, C. (2016). The role of schools in children and young people's self-harm and suicide: Systematic review and meta-ethnography of qualitative research. BMC Public Health, 16(1), 1-16. https://doi.org/10.1186/s12889-016-3065-2. 
Gary, F. A. (2005). Stigma: Barrier to mental health care among ethnic minorities. Issues in Mental Health Nursing, 26(10), 979999. https://doi.org/10.1080/01612840500280638.

Grenyer, B. F. S., Gray, A. S., \& Townsend, M. L. (2016). Working with young people with complex mental health issues: Understanding and responding to emerging personality disorder trauma history, self-harm and suicidal behaviour and difficulties with identity, emotions and relationships. Wollongong: Illawarra Health and Medical Research Institute, University of Wollongong.

Hasking, P. A., Heath, N. L., Kaess, M., Lewis, S. P., Plener, P. L., Walsh, B. W., et al. (2016). Position paper for guiding response to non-suicidal self-injury in schools. School Psychology International, 37(6), 644-663. https://doi.org/10.1177/0143034316 678656.

Hawton, K., \& James, A. (2005). Suicide and deliberate self harm in young people. BMJ, 330(7496), 891-894. https://doi.org/10.1136/ bmj.330.7496.891.

Hawton, K., Saunders, K. E. A., \& O'Connor, R. C. (2012). Self-harm and suicide in adolescents. The Lancet, 379(9834), 2373-2382. https://doi.org/10.1016/s0140-6736(12)60322-5.

Heath, N. L., Toste, J. R., Sornberger, M. J., \& Wagner, C. (2010). Teachers' perceptions of non-suicidal self-injury in the schools. School Mental Health, 3(1), 35-43. https://doi.org/10.1007/s1231 0-010-9043-4.

Laye-Gindhu, A., \& Schonert-Reichl, K. A. (2005). Nonsuicidal selfharm among community adolescents: Understanding the "whats" and "whys" of self-harm. Journal of Youth and Adolescence, 34(5), 447-457. https://doi.org/10.1007/s10964-005-7262-z.

Martin, G., Swannell, S. V., Hazell, P. L., Harrison, J. E., \& Taylor, A. W. (2010). Self-injury in Australia: A community survey. Medical Journal of Australia, 193(9), 506-510. https://doi. org/10.5694/j.1326-5377.2010.tb04033.x.

McGorry, P., Bates, T., \& Birchwood, M. (2013). Designing youth mental health services for the 21st century: Examples from Australia, Ireland and the UK. The British Journal of Psychiatry, 202(s54), s30-s35. https://doi.org/10.1192/bjp.bp.112.119214.

Merikangas, K. R., He, J.-P., Burstein, M., Swendsen, J., Avenevoli, S., Case, B., et al. (2011). Service utilization for lifetime mental disorders in US adolescents: Results of the National Comorbidity Survey-Adolescent Supplement (NCS-A). Journal of the American Academy of Child and Adolescent Psychiatry, 50(1), 32-45. https://doi.org/10.1016/j.jaac.2010.10.006.

Muehlenkamp, J. J., Claes, L., Havertape, L., \& Plener, P. L. (2012). International prevalence of adolescent non-suicidal self-injury and deliberate self-harm. Child and Adolescent Psychiatry and Mental Health, 6(1), 1-9. https://doi.org/10.1186/1753-2000-6-10.

Nock, M. K., Borges, G., Bromet, E. J., Cha, C. B., Kessler, R. C., $\&$ Lee, S. (2008). Suicide and suicidal behavior. Epidemiologic Reviews, 30(1), 133-154. https://doi.org/10.1093/epirev/mxn002.

Nock, M. K., Green, J. G., Hwang, I., McLaughlin, K. A., Sampson, N. A., Zaslavsky, A. M., et al. (2013). Prevalence, correlates, and treatment of lifetime suicidal behavior among adolescents: results from the National Comorbidity Survey Replication Adolescent Supplement. JAMA Psychiatry, 70(3), 300-310. https:// doi.org/10.1001/2013.jamapsychiatry.55.

NSW Department of Education. Incident reports in NSW government schools (2012-2017). Retrieved January 2019, from NSW Department of Education NSW Education Data Hub, https://data.cese. nsw.gov.au/data/dataset/948b732e-fb69-4a8d-a122-78b27ff9ecbe.

O'Connor, R. C., Rasmussen, S., \& Hawton, K. (2012). Distinguishing adolescents who think about self-harm from those who engage in self-harm. British Journal of Psychiatry, 200(4), 330-335. https ://doi.org/10.1192/bjp.bp.111.097808.

Reiss, F. (2013). Socioeconomic inequalities and mental health problems in children and adolescents: A systematic review. Social Science and Medicine, 90, 24-31. https://doi.org/10.1016/j.socsc imed.2013.04.026.

Rickwood, D., Deane, F. P., Wilson, C. J., \& Ciarrochi, J. (2005). Young people's help-seeking for mental health problems. Advances in Mental Health, 4(3), 218-251. https://doi. org/10.5172/jamh.4.3.218.

Toste, J. R., \& Heath, N. L. (2010). School response to non-suicidal self-injury. The Prevention Researcher, 17(1), 14-17.

Townsend, M. L., Gray, A. S., Lancaster, T. M., \& Grenyer, B. F. S. (2018a). A whole of school intervention for personality disorder and self-harm in youth: A pilot study of changes in teachers' attitudes, knowledge and skills. Borderline Personality Disorder and Emotion Dysregulation, 5, 1-17. https://doi.org/10.1186/ s40479-018-0094-8.

Townsend, M. L., Hasleton, S. J., Marceau, E. M., Gray, A. S., \& Grenyer, B. F. S. (2018b). Adolescent intervention: Guide for clinicians. Wollongong: Illawarra Health and Medical Research Institute, University of Wollongong.

Wilson, C. J., \& Deane, F. P. (2010). Help-negation and suicidal ideation: The role of depression, anxiety and hopelessness. Journal of Youth and Adolescence, 39(3), 291-305. https://doi.org/10.1007/ s10964-009-9487-8.

Wilson, C. J., Deane, F. P., Marshall, K. L., \& Dalley, A. (2010). Adolescents' suicidal thinking and reluctance to consult general medical practitioners. Journal of Youth and Adolescence, 39(4), 343-356. https://doi.org/10.1007/s10964-009-9436-6.

Zubrick, S. R., Hafekost, J., Johnson, S. E., Lawrence, D., Saw, S., Sawyer, M., et al. (2016). Self-harm: Prevalence estimates from the second Australian Child and Adolescent Survey of Mental Health and Wellbeing. Australian and New Zealand Journal of Psychiatry, 50(9), 911-921. https://doi.org/10.1177/0004867415 617837.

Publisher's Note Springer Nature remains neutral with regard to jurisdictional claims in published maps and institutional affiliations. 